\title{
Energetic costs, underlying resource allocation patterns, and adaptive value of predator-induced life-history shifts
}

\author{
Karsten Rinke, Stephan Hülsmann and Wolf M. Mooij \\ K. Rinke(karsten.rinke@uni-konstanz.de) and S. Hülsmann, Inst. of Hydrobiology, Dresden Univ. of Technology, DE-01062 Dresden, \\ Germany. Present address for KR: Univ. of Konstanz, Limnological Inst., Mainaustrasse 252, DE-78464 Konstanz, Germany. - W. M. Mooij, \\ Netherlands Inst. of Ecology (NIOO-KNAW), Centre for Limnology, Rijksstraatweg 6, NL-3631 AC Nieuwersluis, the Netherlands.
}

\begin{abstract}
We studied costs and benefits of life history shifts of water fleas (genus Daphnia) in response to infochemicals from planktivorous fish. We applied a dynamic energy budget model to investigate the resource allocation patterns underlying the observed life history shifts and their adaptive value under size selective predation in one coherent analysis. Using a published data set of life history shifts in response to fish infochemicals we show that Daphnia invests less energy in somatic growth in the fish treatment. This observation complies with theoretical predictions on optimal resource allocation. However, the observed patterns of phenotypic plasticity cannot be explained by changes in resource allocation patterns alone because our model-based analysis of the empirical data clearly identified additional bioenergetic costs in the fish treatments. Consequently, the response to fish kairomone only becomes adaptive if the intensity of size selective predation surpasses a certain critical level. We believe that this is the first study that puts resource allocation, energetic costs, and adaptive value of predator induced life-history shifts - using empirical data - into one theoretical framework.
\end{abstract}

A central paradigm of life history theory says that organisms allocate resources in such a way that fitness, measured as the intrinsic rate of natural increase $\mathrm{r}$ or lifetime fecundity $\mathrm{R}_{0}$, is optimized (Stearns 1992). Especially organisms with indeterminate growth, i.e. growth that continues past maturation, constantly face a tradeoff in the allocation of resources between growth and reproduction. This 'dilemma of energy allocation' stimulated a number of theoretical approaches on the evolution of life-histories, which can be viewed as an optimization process for resource allocation (Gadgil and Bossert 1970, Kozlowski 1992). Indeterminate growth is not easy to explain from an evolutionary perspective (Heino and Kaitala 1999); still it is characteristic for many invertebrate taxa like clams, cladocerans and crayfish, 'lower' vertebrate taxa like fish and amphibians, and many plants. In all these organisms the fact that fecundity usually increases with body size constitutes a further tradeoff between current and future reproduction. Consequently, studying the adaptive value of resource allocation patterns is central to life-history theory and this approach has been applied to various organisms like plants (King and Roughgarden 1982), rotifers (Shertzer and Ellner 2002), crustaceans (Gabriel 1982), mussels (Heino and Kaitala 1996), fish (Gadgil and Bossert 1970), and reptiles (Niewiarowski 2001).

Theoretical approaches to elucidate optimal resource allocation predict that in environments with reduced adult survivorship selection is supposed to favor earlier reproduction and increased reproductive effort, i.e. resource alloca- tion into reproduction should be increased on the expense of somatic growth. In environments with reduced juvenile survival selection is supposed to favor an opposite strategy (Law 1979). These divergent life history strategies can be expressed on basis of the genetic differences (either within or between populations, Boersma et al. 1998, Reznick 1982 ) or due to phenotypic plasticity (Riessen 1999, Tollrian and Harvell 1999). A particularly well-suited model organism for investigating the link between energy allocation and life history strategies is Daphnia since on the one hand daphnid physiology has been thoroughly studied and on the other hand daphnids have been shown to adapt their life-history to size-dependent mortality regimes (Boersma et al. 1998, De Meester and Weider 1999). Daphnids are able to sense the type of predator and respond differently to chemical cues (kairomones) released by predators, which prefer different size classes as prey (Riessen 1999). When daphnids were exposed to water previously inhabited by fish (which select large, adult individuals) reproductive effort increased while somatic growth and size at maturity decreased. When they sense invertebrate predators (which select small, juvenile individuals) reproductive effort was reduced while somatic growth and size at maturity increased (Stibor 1992, Stibor and Lüning 1994).

Detailed theoretical studies on optimal resource allocation of Daphnia under different predation regimes predicted these facts qualitatively (Gabriel 1982, Taylor and Gabriel 1992, 1993). However, quantitative outcomes of these investigations were controversial. Only Gabriel (1982) 
was able to reproduce observed life-history adaptations satisfactorily. Taylor and Gabriel (1992) found determinate growth to be optimal although indeterminate growth is typical for Daphnia (Lynch 1980). By adding seasonality to the model, indeterminate growth emerged but only slight adult somatic growth was predicted (Taylor and Gabriel 1993), which still did not quantitatively comply with empirical observations (Stibor 1992, Weider and Pijanowska 1993). All these theoretical approaches follow the same methodology, i.e. to describe the allocation of instantaneous net production between somatic growth and reproduction over the lifespan of an individual. In this respect, net production is defined as the sum of somatic weight increment and egg production per time and usually described by a power function of body size. Accordingly, a basic assumption behind this approach is that this lengthdependent function of net production is valid for all lifehistory strategies and under all predation scenarios.

These facts motivated us to approach the life-historypuzzle from a different angle. We started with empirical observations of life-history shifts and applied an established resource allocation model in order to disentangle underlying patterns in resource allocation. In contrast to earlier studies, we do not intend to find the optimal resource allocation strategy under a given predation regime, i.e. to design an optimal, but imaginary, life-history. Instead, we use empirical observations of life-history shifts of Daphnia galeata $\times$ hyalina and evaluate the allocation patterns underlying these observations by means of a resource allocation model (Rinke and Vijverberg 2005). On the basis of a closed carbon budget over an individual's lifespan we will be able to unravel the accompanying shifts in resource allocation that are associated with an observed life-history shift. Furthermore, our approach enables us to test whether life-history shifts can be fully explained by a shifting allocation strategy alone or whether other bioenergetic costs may come into play. Although our approach necessarily includes a number of assumptions, two important assumptions are relaxed in comparison to former studies: (1) length-dependent net production of an individual does not need to be constant for different life-history strategies - an assumption that has already been questioned by other authors (Spitze et al. 1991), and (2) life-history shifts are completely explainable by a shift in resource allocation.

Another advantage of the approach presented here is that we can account for clonal variation of life-history shifts. It has been shown that Daphnia clones respond differently to environmental cues (Boersma et al. 1998, De Meester and Weider 1999). It therefore appears worthwhile to evaluate under which conditions these different responses become adaptive. This enables us to interpret the observed resource allocation patterns and the resulting life-history shifts in terms of the ecological setting that favors their selection. We evaluated the adaptive value of each strategy by calculating intrinsic rates of population growth under a broad range of predation regimes that are potentially exerted by visually hunting planktivorous fish.

The aims of our study are thus fourfold: (1) to investigate the link between resource allocation patterns and life-history shifts by means of a mechanistical resource allocation model; (2) to apply this model to empirical observations of life-history shifts in several clones of
Daphnia in order to evaluate the resource allocation patterns behind these observations; (3) to quantify potential bioenergetic costs that are associated with the life-history shifts - apart from a plain shift in allocation strategy. Finally, (4) to evaluate how bioenergetic processes associated with the life-history shifts will affect the adaptive value of the observed life-history shift. Although being applied here to Daphnia, our methodology should be valid for various taxa. Overall, this approach proposes a framework to bridge from physiological patterns in resource allocation over individual life-history and its plasticity towards adaptive value and population growth that might have general applicability.

\section{Methods}

\section{Energy allocation model}

We applied an energy allocation model of Daphnia in order to calculate individual life-history (Rinke and Vijverberg 2005). This model has been successfully applied to predict the life-history of $D$. galeata under different food and temperature conditions and was comprehensively validated on experimental data (Rinke and Vijverberg 2005). Model parameters and equations are documented in Table 1 and 2. Assimilated carbon is distributed between growth, maintenance and reproduction according to the concept of Dynamic energy budget (DEB) models (Fig. 1, compare Kooijman 2001). The model fulfills the condition of a closed carbon budget and can be characterized by the central balance equation; assimilation rate (A) equals the sum of maintenance rate $(M)$, somatic growth rate and carbon allocation into reproductive tissue:

$A=M+\frac{d W}{d t}+\frac{d R}{d t}$

Here, the somatic growth rate describes the change in body weight (W) and the term $\mathrm{dR} / \mathrm{dt}$ describes the change in accumulated carbon in gonads (R) over time. A fixed fraction ( $\kappa$, see Fig. 1) of assimilate is allocated in growth and maintenance and the remaining assimilate $(1-\kappa)$ is directed towards reproduction or maturation if the individual is juvenile, respectively. Thus, the change in an individual's body weight over time becomes $\frac{\mathrm{dW}}{\mathrm{dt}}=\kappa \mathrm{A}-\mathrm{M}$ and, accordingly, the change in gonad mass is given by $\frac{\mathrm{dW}}{\mathrm{dt}}=(1-\kappa) \mathrm{A}$.

Carbon is assimilated from the ingested food with efficiency $\mathrm{E}_{\mathrm{A}}$ that depends on food concentration. The ingestion rate scales with squared body length (L) and depends on food concentration through a type II functional response. Maintenance rate scales with body weight, which is proportional to cubed body length. Temperature scaling is realized by an Arrhenius scale. Conditions of constant temperature and food lead to von Bertalanffy growth (von Bertalanffy 1957),

$\mathrm{L}(\mathrm{t})=\mathrm{L}_{\max }-\left(\mathrm{L}_{\max }-\mathrm{L}_{0}\right) \mathrm{e}^{-\mathrm{kt}} \quad$ with: 
Table 1. List of model parameters and variables.

\begin{tabular}{|c|c|c|c|c|}
\hline Parameter & Description & Value & Unit & References \\
\hline W & Body weight & - & $\mu g \mathrm{C}$ & - \\
\hline $\mathrm{L}$ & Body length & - & $\mathrm{mm}$ & - \\
\hline $\mathrm{R}$ & Carbon in gonads & - & $\mu \mathrm{g} \mathrm{C}$ & - \\
\hline $\mathrm{F}$ & Food & - & $\mathrm{mg} \mathrm{Cl}^{-1}$ & - \\
\hline $\mathrm{T}$ & Temperature & - & $\mathrm{K}^{\circ}$ & - \\
\hline $\mathrm{a}$ & length-weight relationship & 1.6 & $\mu \mathrm{g} \mathrm{C} \mathrm{mm}{ }^{-3}$ & $a, b$ \\
\hline $\mathrm{T}_{\text {ref }}$ & reference temperature & 293 & $\mathrm{~K}$ & C \\
\hline $\mathrm{T}_{\mathrm{A}}$ & Arrhenius temperature & 6400 & $\mathrm{~K}$ & d \\
\hline $\mathrm{p}$ & ingestion rate factor & 5.02 & $\mu \mathrm{g} \mathrm{C} \mu \mathrm{g} \mathrm{C}^{-2 / 3} \mathrm{~d}^{-1}$ & a \\
\hline $\mathrm{k}_{\mathrm{F}}$ & half saturation coefficient & 0.164 & $\mathrm{mg} \mathrm{Cl}-1$ & e \\
\hline $\mathrm{E}_{\mathrm{A}, \max }$ & max. assimilation efficiency & 0.9 & dimensionless & $a, f$ \\
\hline $\mathrm{E}_{\mathrm{A}, \min }$ & min. assimilation & 0.5 & dimensionless & $a, f$ \\
\hline $\mathrm{m}_{\mathrm{f}, \max }$ & max. respiration rate & 0.3 & $d^{-1}$ & $b, g$ \\
\hline $\mathrm{m}_{\mathrm{f}, \min }$ & min. respiration rate & 0.15 & $d^{-1}$ & $g, h$ \\
\hline $\mathrm{C}_{\mathrm{E}}$ & carbon investment per egg & 1.3 & $\mu g \mathrm{C} \mathrm{egg}^{-1}$ & $\mathrm{C}$ \\
\hline$\kappa$ & energy allocation factor & 0.35 & dimensionless & C, d, this study \\
\hline SAM & size at maturity & 1.2 & $\mathrm{~mm}$ & C, this study \\
\hline SON & size of neonates & 0.65 & $\mathrm{~mm}$ & C, this study \\
\hline
\end{tabular}

References are: (a) Urabe and Watanabe 1991; (b) Lynch et al. 1986; (c) Rinke and Vijverberg 2005; (d) Kooijman 2000, (e) Muck and Lampert 1984; (f) Porter et al. 1982, (g) Urabe and Watanabe 1990; (h) Bohrer and Lampert 1988.

$\mathrm{L}_{\max }=\frac{\kappa p f(F) E_{A}}{m_{f}} a^{-\frac{1}{3}}$

$\mathrm{k}=\frac{\left(\kappa \mathrm{pf}(\mathrm{F}) \mathrm{E}_{\mathrm{A}} \mathrm{W}_{0}^{\frac{2}{3}}-\mathrm{m}_{\mathrm{f}} \mathrm{W}_{0}\right) \mathrm{f}(\mathrm{T})}{3 \mathrm{aL}_{0}^{2}\left(\mathrm{~L}_{\max }-\mathrm{L}_{0}\right)}$

where $\mathrm{L}_{0}$ and $\mathrm{W}_{0}$ denote body length and body weight of neonates $(\mathrm{age}=0)$. Equations $2 \mathrm{a}-\mathrm{c}$ represent analytical solutions of the applied energy allocation model for somatic growth, which were elaborated in Rinke and Vijverberg (2005).

In our standard parameterization the conversion of carbon within gonads into eggs is accompanied with overheads reflected in the parameter $\mathrm{c}_{\mathrm{E}}$ that describes the carbon investment per egg. In Daphnia, the deposition of eggs only occurs directly after molting and the eggs are kept within the brood chamber until the next molt when they are released as neonates, i.e. instar duration almost equals egg development time (Bottrell 1975). Thus, the current clutch size represents the accumulated egg production over the previous molting cycle. Consequently, clutch size $\mathrm{E}$ at instar no. $\mathrm{n}+1$ becomes

Table 2. Specification of the used energy allocation model.

\begin{tabular}{ll}
\hline Description & Formula \\
\hline $\begin{array}{l}\text { Length-weight relationship } \\
\text { Ingestion rate }\end{array}$ & $\begin{array}{l}\mathrm{W}=\mathrm{a} \times \mathrm{L}^{3} \\
\mathrm{I}=\mathrm{p} \times \mathrm{W}^{2 / 3} \times \mathrm{f}(\mathrm{F}) \times \mathrm{f}(\mathrm{T}) \\
\text { Functional response }\end{array}$ \\
& $\mathrm{f}(\mathrm{F})=\frac{\mathrm{F}}{\mathrm{F}+\mathrm{k}_{\mathrm{F}}}$ \\
Temperature scaling & $\mathrm{f}(\mathrm{T})=\mathrm{e}\left(\frac{\mathrm{T}_{\mathrm{A}}}{\mathrm{T}_{\mathrm{ref}}}-\frac{\mathrm{T}_{\mathrm{A}}}{\mathrm{T}}\right)$ \\
Assimilation rate & $\mathrm{A}=\mathrm{I} \times \mathrm{E}_{\mathrm{A}}$ \\
Assimilation efficiency & $\mathrm{E}_{\mathrm{A}}=\mathrm{E}_{\mathrm{A}, \max }-\left(\mathrm{E}_{\mathrm{A}, \max }-\mathrm{E}_{\mathrm{A}, \min }\right) \times \mathrm{f}(\mathrm{F})$ \\
Maintenance rate & $\mathrm{M}=\mathrm{m}_{\mathrm{f}} \times \mathrm{W} \times \mathrm{f}(\mathrm{T})$ \\
& $\mathrm{m}_{\mathrm{f}}=\mathrm{m}_{\mathrm{f}, \min }+\left(\mathrm{m}_{\mathrm{f}, \max }-\mathrm{m}_{\mathrm{f}, \min }\right) \times \mathrm{f}(\mathrm{F})$ \\
Egg production before molt & $\mathrm{E}=\frac{\mathrm{R}}{\mathrm{C}_{\mathrm{E}}}$ \\
\hline
\end{tabular}

*set $\mathrm{R}=0$ after release of eggs. the integral of accumulated carbon into gonads over the instar no. $n$, i.e. the time between $t_{0}$ and $t_{1}$, divided by $c_{E}$.

$E=\int_{t 0}^{\mathrm{t}=\mathrm{t} 0+\mathrm{D}} \frac{(1-\kappa) \mathrm{A}(\mathrm{W}, \mathrm{T}, \mathrm{F})}{\mathrm{c}_{\mathrm{E}}} \mathrm{dt}$

where $\mathrm{D}$ denotes egg development time that depends on temperature $\mathrm{T}^{\circ} \mathrm{C}$ (Bottrell et al. 1976): $\mathrm{D}=\exp (3.395+$ $\left.0.2193 \times \ln \left(\mathrm{T}^{\circ} \mathrm{C}\right)-0.3414 \times\left(\ln \left(\mathrm{T}^{\circ} \mathrm{C}\right)\right)^{2}\right)$. Only parthenogenetic reproduction of Daphnia has been considered. We defined the size at maturity (SAM) as the size at which maturation is completed and carbon allocated into reproduction is used for egg production (whereas earlier it is used for maturation). On the other hand, size at first reproduction (SFR) was defined as the size of the instar at which eggs are deposited in the brood chamber for the first time (Stibor and Lampert 1993).

\section{Patterns in resource allocation with respect to life-history shifts}

We first investigated the effect of variation of the energy allocation factor $\kappa$ on individual somatic growth and egg production, i.e. demonstrating the sensitivity of model outputs against variation in $\kappa$. We then applied this model to empirical data from laboratory experiments. Previous studies have shown that life-history responses to predator infochemicals differ among clones (Boersma et al. 1998, De

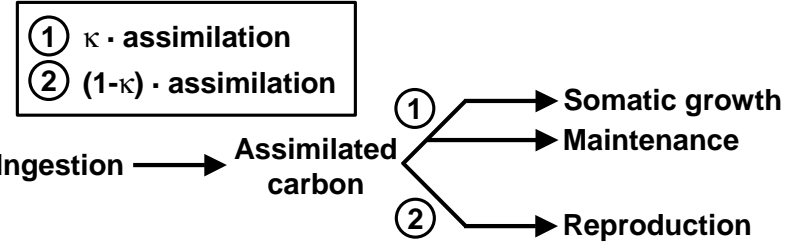

Fig. 1. Flow chart of energy allocation in the applied energy allocation model. A fixed fraction of assimilate is allocated into somatic growth and maintenance $(\kappa)$ and the remaining assimilate $(1-\kappa)$ is committed to reproduction/maturation. 
Meester and Weider 1999). We therefore accounted for clonal diversity by applying our model separately to lifehistory data of 22 clones of $D$. hyalina $\times$ galeata as provided by De Meester and Weider (1999). These data were considered particularly appropriate for our research question because: (1) they studied several clones, and (2) they used preconditioned animals whose mothers had also been exposed to kairomones. The latter is important because kairomones also affect size of neonates and measuring a transitional state can only be avoided by using preconditioned animals (De Meester et al. 1999). In their study, clones showing a behavioral response to fish kairomone ('risk-averse', that is, residing in deeper water layers during daylight and coming up at night, clone 10-22) were distinguished from those without a behavioral response ('risk-tolerant', that is, staying permanently in upper water layers, clone 1-9). Experiments of De Meester and Weider (1999) were conducted at $20^{\circ} \mathrm{C}$ and a food level of $1 \mathrm{mg} \mathrm{C}$ $\mathrm{l}^{-1}$. Accordingly, all model calculations using their data were performed at these constant temperature and food conditions.

The following life-history characteristics were provided by De Meester and Weider (1999): size at first reproduction (SFR), size of neonates (SON), age at first reproduction (AFR), and number of eggs in first clutch (NEFC). Length measurements were carried out from the top of the eye to the base of the tail spine (EL). We converted this into total body length - the respective length measure in our model on basis of own measurements $\left(\mathrm{TL}=1.07 \times \mathrm{EL}, \mathrm{r}^{2}=\right.$ $0.998, \mathrm{n}=55$ ). We assumed all model parameters involved in resource acquisition and maintenance to be equal for all clones. Only two model parameters, the energy allocation factor $\kappa$ and carbon investment per egg $c_{E}$, had to be adjusted in order to simulate observed life-histories. Parameter $\kappa$ was estimated using Eq. $2 \mathrm{a}-\mathrm{c}$ by searching a value of $\kappa$ that satisfied the requirement to reach SFR at the age of AFR with the body length SON at age zero. For estimating the carbon investment per egg one first has to determine the size at maturity (SAM). In Daphnia, gonads are becoming ripe during two instars (commonly considered as preadult instars) before eggs are deposited into the brood pouch (Zaffagnini 1987). Since 'juvenile' instars are roughly half as long as adult instars (egg development time, Bottrell 1975), age at maturity becomes $\mathrm{AAM}=\mathrm{AFR}-\mathrm{D}$. Once $\mathrm{AAM}$ is known, SAM can be calculated by Eq. 2a-c. We then calculated carbon accumulated in gonads over the duration from AAM to AFR and divided this mass by the number of eggs in the first clutch in order to achieve an estimate of $\mathrm{c}_{\mathrm{E}}$.

$$
\mathrm{c}_{\mathrm{E}}=\frac{1}{\mathrm{NEFC}} \int_{\mathrm{AAM}}^{\mathrm{AFR}}(1-\kappa) \mathrm{A}(\mathrm{SAM}, \mathrm{T}, \mathrm{F}) \mathrm{dt}
$$

\section{Size selective predation and population growth}

Fish feeds selectively on large zooplankton prey and survival probability declines with increasing size (Werner and Hall 1974). In order to account for this size selective feeding we assumed a sigmoid relationship between body size and mortality rate d (compare Spaak et al. 2000, Taylor and Gabriel 1992):

$\mathrm{d}=\mathrm{d}_{\text {background }}+\mathrm{d}_{\text {deflection }}\left(1+\tanh \left(\mathrm{d}_{\text {slope }}\left(\mathrm{L}-\mathrm{L}_{\text {mid }}\right)\right)\right)$

where $\mathrm{d}_{\text {background }}$ is non-selective background mortality $\left(0.05 \mathrm{~d}^{-1}\right), \mathrm{d}_{\text {deflection }}$ describes the deflection of the tanhfunction, $d_{\text {slope }}$ is the slope in the sigmoid function $\left(41^{-1}\right.$ according to Köpke et al. 1988), and $\mathrm{L}_{\text {mid }}$ depicts the point of inflection. Parameters $\mathrm{L}_{\text {mid }}$ and $\mathrm{d}_{\text {deflection }}$ are well interpretable in an ecological sense and, therefore, were varied over a reasonable range reflecting different predation regimes (Fig. 2). In the predation intensity scenario we studied the effects of variation of $d_{\text {deflection }}$ on fitness; in the size-selectivity scenario the effects of variation of $\mathrm{L}_{\text {mid }}$ were analyzed. We considered $d_{\text {deflection }}$ to represent the intensity of predation being related to the abundance of planktivorous fish, which changes seasonally due to the occurrence of young-of-the-year (YOY) fish. The parameter $\mathrm{L}_{\text {mid }}$ is related to the selectivity of the predator, which changes during ontogeny. The most dramatic changes occur in YOY fishes which progressively feed on larger prey as they grow during their first season (Mehner et al. 1998, Wahl et al. 1993). In several studies (Cryer et al. 1986, Mills and Forney 1983, Wagner et al. 2004), YOY fish were found to represent the main vertebrate predators of daphnids.

Finally, we calculated complete life-histories for each clone by using the adjusted resource allocation model providing the instar-specific maternity function $\mathrm{m}_{\mathrm{a}}$. Survival probability $l_{a}$ of the consecutive instars was calculated by numerically integrating mortality rate $d$ over age a. Because body length of individuals changes stepwise over time (at molting) mortality rate $\mathrm{d}$ becomes a function of age and survival probability under fish predation will be:

$l_{a}=\exp \left(\int_{a=0}^{n} d(L(a)) d a\right)$
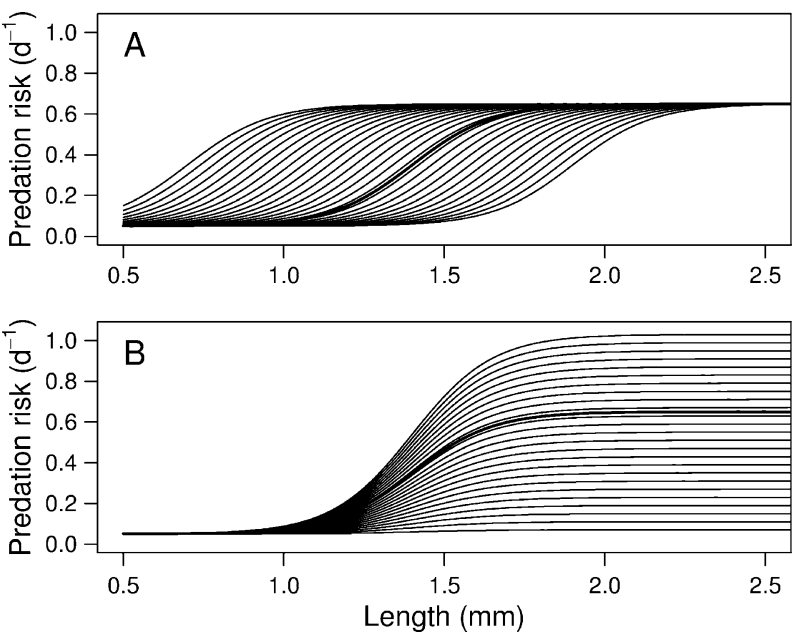

Fig. 2. The predation risk in the predation regimes applied. The bold printed line depicts the standard scenario from which the different regimes were derived by varying either the predator's size (A) or the predator's abundance (B). 
where $\mathrm{n}$ is the individual lifespan, which was set to a value allowing each clone to release 9 clutches. Finally, population growth rate $r$ was calculated by solving the Euler equation for the first 9 adult clutches:

$1=\sum 1_{\mathrm{a}} \mathrm{m}_{\mathrm{a}} \mathrm{e}^{-\mathrm{ra}}$.

\section{Results}

\section{Linking resource allocation to life-history}

Life-history characteristics like somatic growth and agedependent egg production are closely linked to the underlying resource allocation strategy (Fig. 3). Lowering the value of $\kappa$, which corresponds to a higher allocation of resources to reproduction, resulted in reduced growth and a lower maximal body size an individual can reach (Fig. 3A). If age at maturity is kept constant, such a strategy leads to a reduced size at maturity (Fig. 3B). At the same time clutch size at a given length is higher because more energy is channeled into reproduction (Fig. 3B).

\section{Resource allocation patterns and associated costs in observed life-history shifts}

Our model-based analysis of the life-history data recorded by De Meester and Weider (1999) revealed a decreased resource allocation towards somatic growth in animals exposed to fish infochemicals (Table 3). All clones showed a consistent response in the fish treatment by reducing the energy allocation factor $\kappa$ when compared with control conditions (Welch two sample t-test, $\mathrm{p}<0.001$; Fig. $4 \mathrm{~A}-$ B). However, although all clones showed a reaction in the same direction, the intensity of this response varied and in the case of two clones even seemed to be negligible (clones 7 and 18). As a consequence of this differential response, variability between phenotypes increased in the fish treatment. Interestingly, 14 out of 22 clones also showed an increase in the carbon investment per egg (parameter $\mathrm{c}_{\mathrm{E}}$ ), although all clones consistently reduced the size of their offspring in the fish treatment (Fig. 4C-D). Thus, only the remaining eight clones showed a response in parameter $\mathrm{c}_{\mathrm{E}}$ that is expected from the respective change in size of neonates. Due to this unequal response, parameter $\mathrm{c}_{\mathrm{E}}$ was on average not significantly increased in the fish treatments (Welch two sample t-test, $\mathrm{p}=0.11$ ). However, close inspection of the data showed those life-history realizations with a low $\kappa$ to have a high value of the parameter $\mathrm{c}_{\mathrm{E}}$. An ANCOVA with $c_{E}$ as response variable and $\kappa$ as independent variable revealed a significant increase of $c_{E}$ with decreasing $\kappa$ (ANCOVA, DF $=1, \mathrm{~F}=32.6, \mathrm{p}<0.001$ ). Generally speaking, clones reacting to fish kairomone with a strong shift in their life-history, i.e. a strong reduction of $\kappa$, experience at the same time a strong increase in $\mathrm{c}_{\mathrm{E}}$.

An increased carbon investment per egg, as reflected by the parameter $c_{E}$, indicates the appearance of additional costs on the bioenergetic level (note that our parameterization procedure associates these costs with egg production but other sources of the bioenergetic costs are equally likely, see online appendix). To unravel the consequences of these bioenergetic costs at the population level, model outputs were used to calculate population growth rates for all clones and treatments under the assumption of a slight background mortality of $0.05 \mathrm{~d}^{-1}$ (i.e. no size-selective predation). These population growth rates varied over a considerable range $\left(0.18-0.33 \mathrm{~d}^{-1}\right)$. In fact, 18 out of 22 clones realized a reduced population growth rate in the fish treatments. If the calculated population growth rates are compared with the respective energy allocation factor $\kappa$, it emerges that there is a significant trend to higher growth rates with increasing $\kappa$ (Fig. 5A). Consistently, we also found a significant negative relationship between population growth rate and the carbon investment per egg (Fig. 5B) reflecting the consequences of the costs on the bioenergetic level. These results indicate that those clones that reduce their somatic growth to a very low level in response to fish kairomone, i.e. realizing a low $\kappa$, do suffer elevated costs on the bioenergetic level, which finally leads to a severely reduced population growth rate under conditions of non-selective predation.

\section{Adaptive value of life-history shifts}

Population growth rates decreased with increasing predation intensity and with progressive selection of smaller individuals (Fig. 6, 7). Clones performed differently over the range of predation regimes tested. In the predation intensity scenario (varying $\mathrm{d}_{\text {deflection, }}$ Fig. 6) all clones
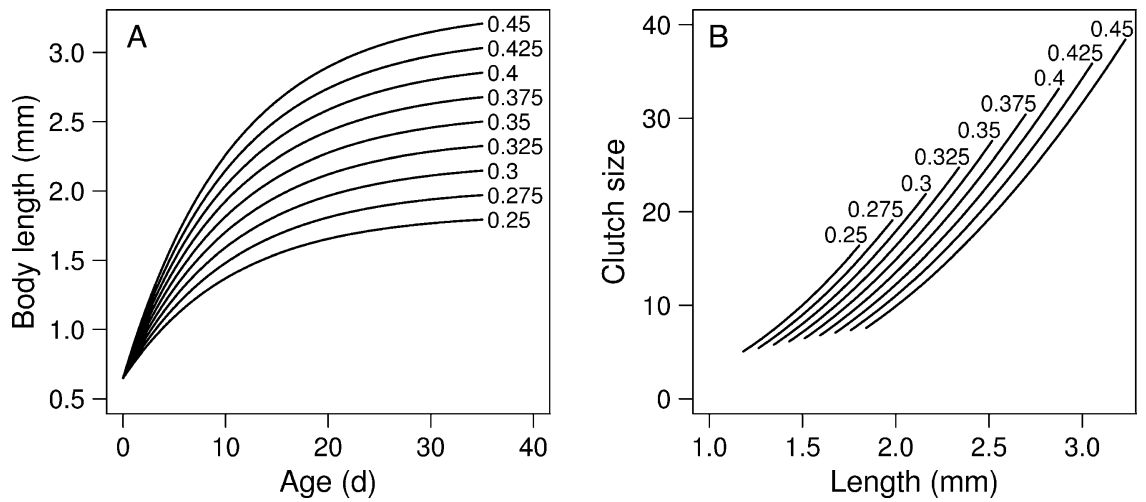

Fig. 3. Somatic growth (A) and egg production (B) of Daphnia having different energy allocation strategies as reflected in the energy allocation factor $\kappa$. Values of $\kappa$ are indicated at the upper end of the lines. 


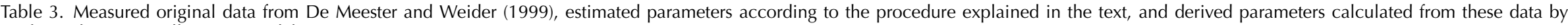
applying the energy allocation model.

\begin{tabular}{|c|c|c|c|c|c|c|c|c|c|}
\hline \multirow[t]{2}{*}{ Clone } & \multicolumn{5}{|c|}{ Measured data } & \multicolumn{2}{|c|}{ Estimated parameters } & \multicolumn{2}{|c|}{ Derived parameters } \\
\hline & Treatment & SFR $[\mathrm{mm}]$ & $\mathrm{SON}[\mathrm{mm}]$ & AFR [mm] & NEFC [eggs] & $\kappa$ & $C_{E}\left[\mu g C\right.$ egg $\left.^{-1}\right]$ & $\mathrm{L}_{\max }[\mathrm{mm}]$ & $\mathrm{SAM}[\mathrm{mm}]$ \\
\hline 1 & control (fish) & $1.37(1.26)$ & $0.56(0.55)$ & $5.51(6.14)$ & $4.70(4.01)$ & $0.352(0.296)$ & $1.29(1.53)$ & $2.59(2.18)$ & $1.03(0.99)$ \\
\hline 2 & control (fish) & $1.38(1.30)$ & $0.55(0.55)$ & $5.64(5.51)$ & $5.25(5.25)$ & $0.352(0.328)$ & $1.18(1.08)$ & $2.59(2.41)$ & $1.04(0.98)$ \\
\hline 3 & control (fish) & $1.40(1.22)$ & $0.56(0.54)$ & $5.64(6.64)$ & $5.72(3.02)$ & $0.356(0.275)$ & $1.10(2.10)$ & $2.62(2.02)$ & $1.06(1.00)$ \\
\hline 4 & control (fish) & $1.42(1.27)$ & $0.57(0.56)$ & $5.51(6.51)$ & $4.97(2.51))$ & $0.366(0.289)$ & $1.27(2.64)$ & $2.69(2.13)$ & $1.06(1.03)$ \\
\hline 5 & control (fish) & $1.43(1.24)$ & $0.57(0.54)$ & $5.51(6.51)$ & $6.21(3.98)$ & $0.368(0.281)$ & $1.01(1.59)$ & $2.71(2.07)$ & $1.06(1.00)$ \\
\hline 6 & control (fish) & $1.45(1.28)$ & $0.55(0.52)$ & $5.51(5.34)$ & $6.97(3.00)$ & $0.379(0.334)$ & $0.89(1.73)$ & $2.79(2.46)$ & $1.07(0.94)$ \\
\hline 7 & control (fish) & $1.49(1.42)$ & $0.57(0.54)$ & $5.38(5.01)$ & $6.71(6.48)$ & $0.395(0.394)$ & $0.94(0.82)$ & $2.91(2.90)$ & $1.09(1.00)$ \\
\hline 8 & control (fish) & $1.49(1.28)$ & $0.55(0.50)$ & $5.38(4.89)$ & $6.71(5.25)$ & $0.400(0.357)$ & $0.92(0.86)$ & $2.95(2.63)$ & $1.08(0.89)$ \\
\hline 9 & control (fish) & $1.50(1.40)$ & $0.57(0.55)$ & $5.26(5.14)$ & $6.97(5.74)$ & $0.403(0.377)$ & $0.89(0.97)$ & $2.96(2.77)$ & $1.08(1.01)$ \\
\hline 10 & control (fish) & $1.31(1.28)$ & $0.56(0.55)$ & $5.64(5.74)$ & $3.81(3.39)$ & $0.326(0.314)$ & $1.56(1.73)$ & $2.40(2.31)$ & $1.00(0.98)$ \\
\hline 11 & control (fish) & $1.38(1.28)$ & $0.56(0.55)$ & $5.50(5.74)$ & $4.77(4.56)$ & $0.355(0.312)$ & $1.27(1.29)$ & $2.61(2.30)$ & $1.03(0.99)$ \\
\hline 12 & control (fish) & $1.47(1.34)$ & $0.56(0.53)$ & $5.12(5.50)$ & $5.31(6.05)$ & $0.403(0.349)$ & $1.09(0.94)$ & $2.97(2.56)$ & $1.05(0.99)$ \\
\hline 13 & control (fish) & $1.48(1.31)$ & $0.54(0.52)$ & $5.36(5.26)$ & $7.55(6.05)$ & $0.399(0.348)$ & $0.80(0.86)$ & $2.93(2.56)$ & $1.07(0.95)$ \\
\hline 14 & control (fish) & $1.48(1.35)$ & $0.56(0.55)$ & $5.40(5.50)$ & $6.05(4.35)$ & $0.393(0.348)$ & $1.03(1.35)$ & $2.89(2.56)$ & $1.08(1.01)$ \\
\hline 15 & control (fish) & $1.49(1.35)$ & $0.56(0.52)$ & $5.26(5.12)$ & $7.23(5.84)$ & $0.404(0.368)$ & $0.84(0.88)$ & $2.97(2.71)$ & $1.07(0.96)$ \\
\hline 16 & control (fish) & $1.51(1.37)$ & $0.55(0.53)$ & $5.50(5.12)$ & $6.80(5.31)$ & $0.399(0.372)$ & $0.94(1.00)$ & $2.94(2.74)$ & $1.10(0.98)$ \\
\hline 17 & control (fish) & 1.51 (1.40) & $0.56(0.55)$ & $5.12(5.26)$ & $7.97(6.59)$ & $0.415(0.375)$ & $0.74(0.86)$ & $3.06(2.76)$ & $1.07(1.02)$ \\
\hline 18 & control (fish) & $1.51(1.42)$ & $0.58(0.55)$ & $5.64(5.16)$ & $4.24(5.52)$ & $0.388(0.387)$ & $1.61(1.01)$ & $2.86(2.84)$ & $1.12(1.02)$ \\
\hline 19 & control (fish) & $1.57(1.30)$ & $0.58(0.54)$ & $5.50(5.74)$ & $5.52(5.09)$ & $0.416(0.324)$ & $1.23(1.16)$ & $3.06(2.38)$ & 1.15 (1.00) \\
\hline 20 & control (fish) & $1.61(1.42)$ & $0.60(0.58)$ & $5.50(5.50)$ & $6.37(4.56)$ & $0.422(0.364)$ & $1.11(1.39)$ & 3.11 (2.68) & $1.18(1.06)$ \\
\hline 21 & control (fish) & $1.63(1.42)$ & $0.63(0.59)$ & $5.40(5.26)$ & $5.31(4.56)$ & $0.431(0.373)$ & $1.35(1.32)$ & $3.17(2.74)$ & $1.19(1.04)$ \\
\hline 22 & control (fish) & $1.63(1.40)$ & $0.63(0.57)$ & $5.74(5.12)$ & $7.76(6.27)$ & $0.415(0.375)$ & $1.00(0.91)$ & $3.06(2.76)$ & $1.23(1.02)$ \\
\hline
\end{tabular}



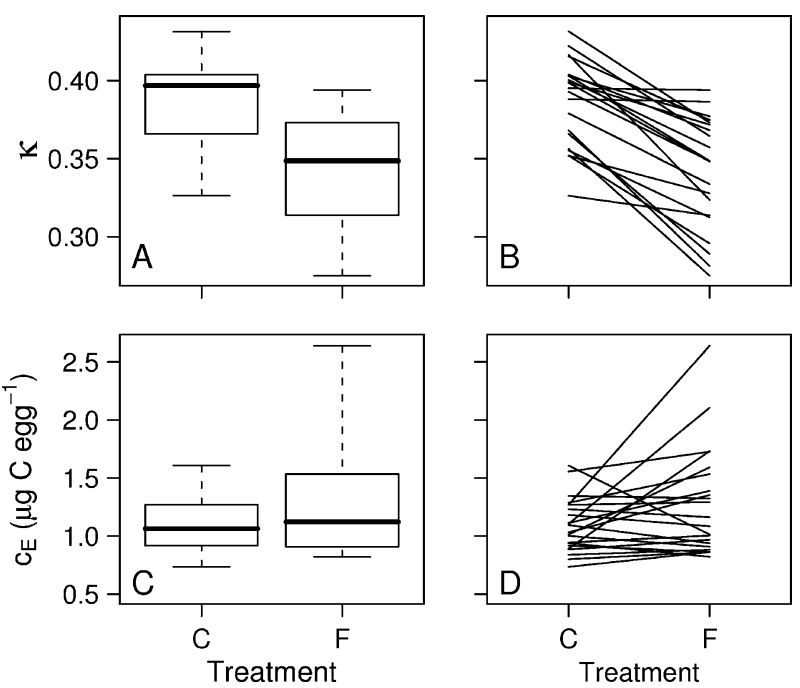

Fig. 4. Energy allocation factor and carbon investment per egg as estimated from the 22 clones studied in De Meester and Weider (1999): boxplots (A) and clone-specific responses (B) of the energy allocation factor $\kappa$ in both groups of treatments and the respective responses in the parameter $\mathrm{c}_{\mathrm{E}}$ (carbon investment per egg, $(\mathrm{C})$ and (D)); treatments: $\mathrm{F}=$ animals exposed to fish kairomone; $\mathrm{C}=$ control animals; $\mathrm{n}=22$.

revealed an adaptive value of their life-history shifts. The critical predation intensity that has to be surpassed to make the life-history shift adaptive (i.e. the crossing point in Fig. 6) is highly variable between clones. It is possible though to categorize the clones into three classes according to their response to predator infochemicals. For one group of clones (e.g. clone 7) the observed life history responses to fish infochemicals were found to be always adaptive. The population growth rate of these clones was always higher for the life-history strategy expressed in the presence of fish, no matter which predation scenario was applied. These clones were found to have no or negligible costs arising from the life-history shift (no increase of the parameter $c_{E}$ in the fish treatments). In total, 4 clones could be grouped into this category. In a second group consisting of 3 clones (no. 3, 4 and 6) quite the opposite was observed: the life history responses to fish were only adaptive under very high fish predation levels. In the predation intensity scenario the lines of $\mathrm{r}$ of both life-history strategies did cross at high predation intensities for these clones, indicating that only under very intense predation the life history shifts did become adaptive (Fig. 6). In the size-selectivity scenario (varying $\mathrm{L}_{\text {mid }}$ ) $\mathrm{r}$ was found to be always higher for the lifehistory displayed under control conditions (Fig. 7). Supplementary bioenergetic costs of life history shifts in these clones are considerable (strong increase in the parameter $\left.\mathrm{c}_{\mathrm{E}}\right)$. The third group of clones was intermediate between the first two groups, with fish-induced life-history shifts becoming adaptive at low-moderate predation levels, which is indicated by a moderate increase of the parameter $\mathrm{C}_{\mathrm{E}}$ in the fish treatments (e.g. clone 5). Overall, 15 clones belonged to this group. Finally, our results also show that the adaptive value of life-history shifts is more sensitive against variation of predation intensity than against variation in size selectivity.

These results show that a distinct size-selective predation intensity is necessary in order to make the supplementary bioenergetic costs of the observed life-history shifts pay off. The critical predation intensity necessary to turn the lifehistory shift into an adaptive response varies between clones and scales with the magnitude of the supplementary costs (Fig. 8A). Particularly such clones that showed a strong reduction of the energy allocation into somatic growth, i.e. lowering $\kappa$ significantly, on average also suffered higher supplementary costs, and therefore realized an adaptive value of their life-history shift only under rather high predation intensities. There is, in fact, a tradeoff between changing the resource allocation by reducing $\kappa$, i.e. to minimize the effective predation window on the population by reducing somatic growth, and emerging supplementary costs as expressed in an increased carbon investment per egg. In order to draw a more generalized picture of this tradeoff, the trait-space realized by the nine clones was evaluated by a simulation study. This was done by defining an average individual from the control animals and simulating different possible life-history shifts of this average individual by applying different relative changes in the parameters $\kappa$ and $c_{\mathrm{E}}$. Finally, for all these life-history shifts the critical predation intensity was calculated. The emerging pattern showed that strong changes in resource allocation do only pay off if size-selective predation in the environment is intense (Fig. 8B). However, there is still a
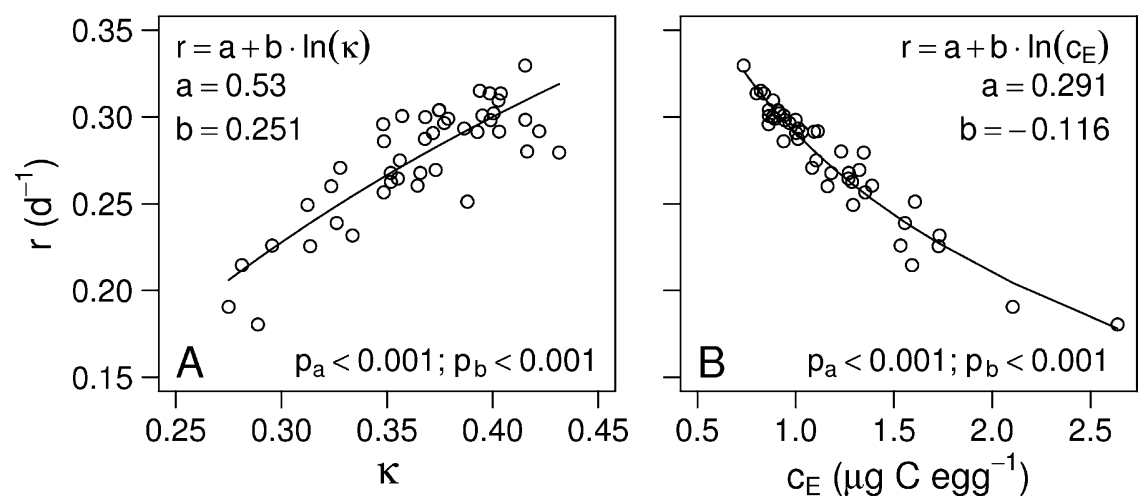

Fig. 5. (A) Non-linear regression between energy allocation factor $\kappa$ and the population growth rate $\mathrm{r}$ of each clone and treatment as calculated by the model $\left(r^{2}=0.71, D F=42\right)$. (B) Non-linear regression between parameter $c_{E}$ and the population growth rate $r$ of each clone and treatment as calculated by the model $\left(r^{2}=0.93, D F=42\right)$. 


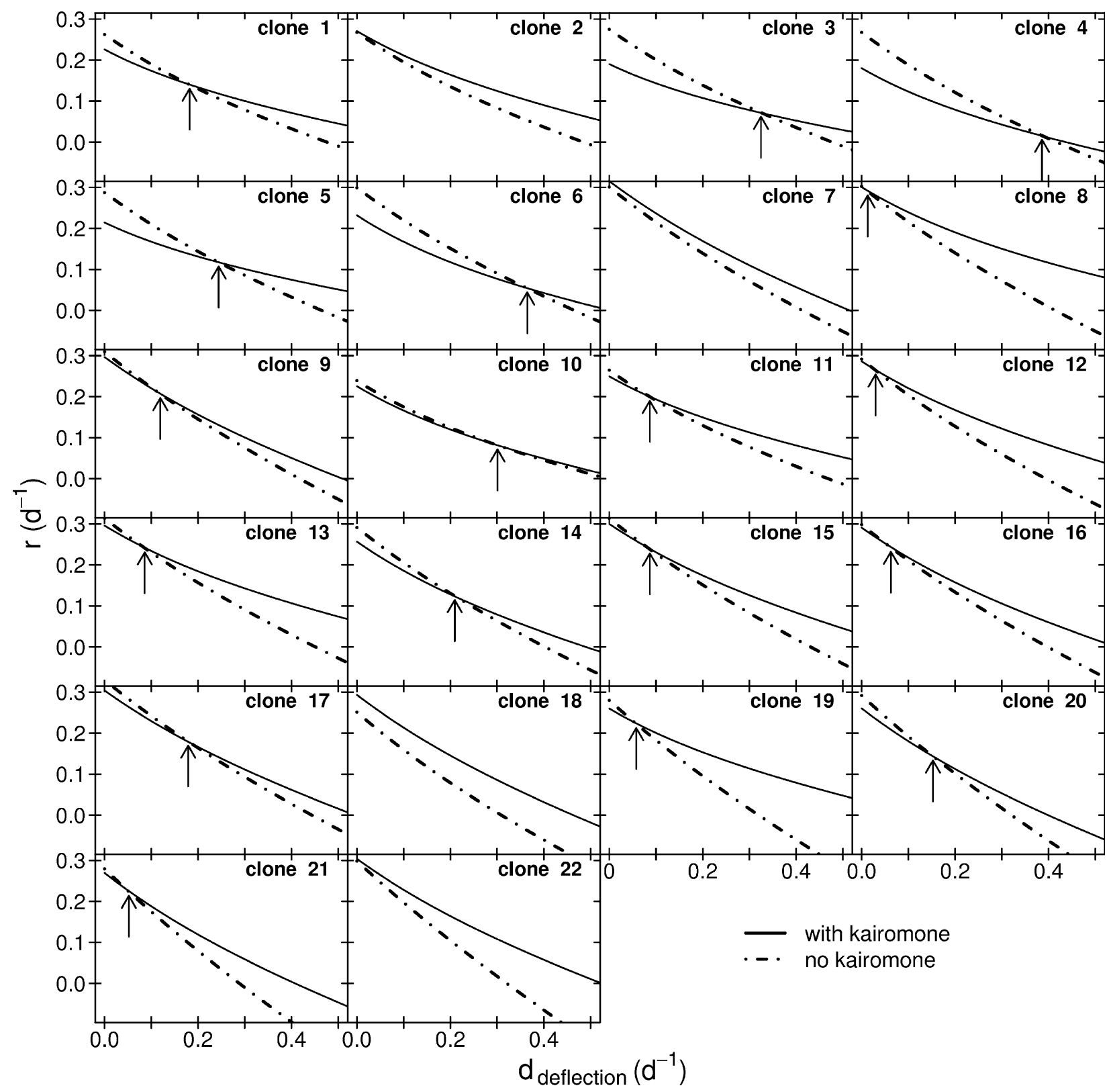

Fig. 6. Clone-specific population growth rates $r$ at varying predation intensities as displayed by the predation model parameter $d_{\text {deflection }}$ A value of zero for $d_{\text {deflection }}$ corresponds to non-selective predation. Lines represent different life-history strategies of the clones: either the life-history expressed in control treatments (no kairomone, dashed line) or the life-history expressed in fish treatments (with kairomone, solid line). The intersection point of both lines (arrows) points to the critical predation intensity, which has to be surpassed in order to make the life-history shift adaptive.

large region in the trait space where a life-history shift is not costly and always adaptive under size selective predation (having negative values for the critical predation intensity). This region is indicated by the isoline for a critical predation intensity of zero, which separates costly (above this isoline) from non-costly life-history shifts (below this isoline).

\section{Discussion}

This study gives strong support to the hypothesis that predator-induced phenotypic life history responses result from a shift in the underlying resource allocation as represented by the parameter $\kappa$ in the applied model. It is shown that in response to fish kairomones the allocation of resources to somatic growth is decreased (by reducing $\kappa$ ), resulting in slower somatic growth, reduced size at maturity and increased investment into reproduction, which corresponds to empirical observations (Stibor 1992). However, by using observations of life-history shifts in 22 clones of Daphnia for a quantitative evaluation of the underlying resource allocation pattern, it explicitly emerged that a change in the energy allocation factor $\kappa$ was not in all clones sufficient to explain the observed life-history shifts. In at least nine clones, besides a change in $\kappa$, considerable costs 


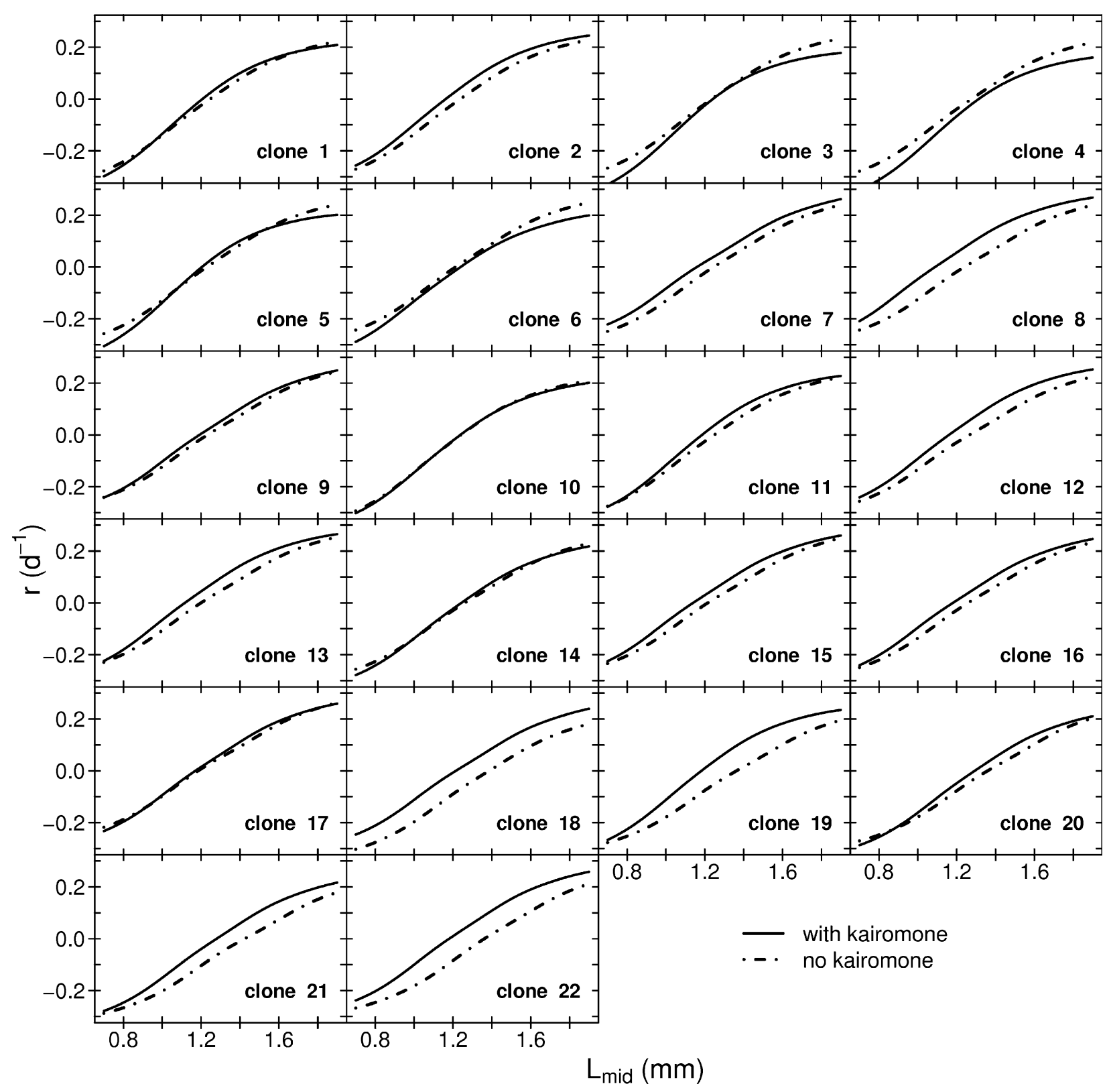

Fig. 7. Clone-specific population growth rates $r$ at varying size selection behavior of the predator as displayed by the predation model parameter $\mathrm{L}_{\text {mid }}$. Lines represent different life-history strategies of the clones as indicated in the caption of Fig. 6.

on the bioenergetic level have been detected that appeared to be associated with the life-history shift. Since the costs rise if a strong shift in the energy allocation takes place this finding reveals a tradeoff involved in the life-history shift. Our approach does not only account for shifts in resource allocation and facilitates the quantification of potentially associated supplementary costs; it even enables to interpret the consequences of all these individual level processes in terms of fitness, thereby putting the results in an evolutionary context. The methodology of our approach can be easily applied to other model organisms where basic lifehistory parameters (at least the size of neonates, size and age at maturity, and number of offspring) are known and a good model-based understanding of energy allocation is available.

\section{Implications of model assumptions and causes of bioenergetic costs}

The specific model we used here is among the best validated approaches for Daphnia over a broad range of environmental conditions (Rinke and Vijverberg 2005). The employed resource allocation model follows the assumptions of dynamic energy budget models (Kooijman 2000), e.g. length-scaling of ingestion (proportional to $\mathrm{L}^{2}$ ) and maintenance rates (proportional to $\mathrm{L}^{3}$ ) and the application of a constant energy allocation factor $\kappa$ ( $\kappa$-rule, Kooijman 2001). At first glance, especially the latter assumption seems hard to defend from an empirical point of view. However, Noonburg and Nisbet (2005) recently affirmed that the application of fixed allocation factors is optimal for a broad 

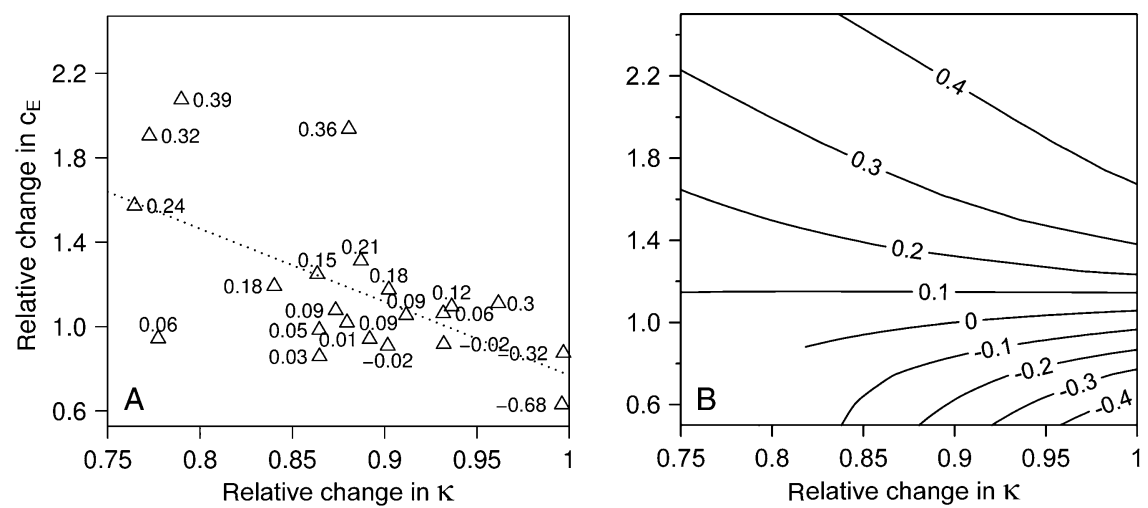

Fig. 8. (A) Relative change in the energy allocation factor $\kappa$ of all Daphnia-clones plotted against the respective relative change in the carbon investment per egg $\mathrm{c}_{\mathrm{E}}$ (points) and the corresponding linear regression model calculated from these data (dotted line, $\mathrm{y}=$ $-3.48 \mathrm{x}+4.24, \mathrm{p}=0.003, \mathrm{n}=22$ ). Relative changes were calculated as the respective parameter value in the fish treatment divided by the corresponding value from the control treatment. Numbers close to data points indicate the critical predation intensity. (B) Critical predation intensities (isolines) of an average individual calculated from a simulation study over a range of possible life-history shifts as defined by the respective relative change in the parameters $\kappa$ and $\mathrm{c}_{\mathrm{E}}$ over the trait space covered by the 22 Daphnia-clones.

class of life-histories and from a theoretical point of view the $\kappa$-rule is a parameter-sparse way to model life-histories (Kooijman 2001, Nisbet et al. 2000). Successful applications of the $\kappa$-rule have been shown to various taxa like mussels (Ren and Ross 2005), crustaceans (Kooijman 1986), and fish (van der Veer et al. 2003). In conclusion, we consider the incorporation of the mentioned assumptions on dynamics of resource acquisition and usage into our model fully in line with the existing literature on Daphnia.

Another aspect of our analysis that deserves careful inspection is the order of evaluation in our procedure to estimate $\kappa$ and $\mathrm{c}_{\mathrm{E}}$. Both parameters are related to each other through the closed carbon budget, given our assumption of food acquisition and maintenance to be equal for all clones. The way we estimated both parameters (first $\kappa$ using Eq. 2c then $c_{E}$ using Eq. 4) implies that parameter $c_{E}$ as the last free parameter includes all variation in physiological processes between and within the clones. Consequently, we can indeed interpret any increase in $\mathrm{C}_{\mathrm{E}}$ as a cost but we can not deduce that these costs are necessarily associated with reproduction. Instead, they might be related to increased maintenance costs, e.g. due to thicker carapaces (Laforsch et al. 2004) or increased alertness (Brewer et al. 1999). Alternatively, costs could also be caused by a reduced resource acquisition rate (Ramcharan et al. 1992) in consequence of a behavioral response to reduce the risk of being detected by the predator. Interestingly, the recent work by Beckerman et al. (2007) indeed found a reduced energy intake of Daphnia in response to fish kairomones. The fact that physiological properties of a prey organism change in response to predation is known from many other systems. For example, tadpoles modulate their activity level, which interacts with their food intake, in response to larval dragonfly predators (Richardson 2001a, 2001b). Comparable results were found in larvae of the damselfly Ischnura, which modulate their assimilation efficiency in order to compensate for predation effects from dragonfly larvae (McPeek 1998, 2004). We explored alternative parameterizations that attributed the bioenergetic costs to either elevated maintenance or reduced food intake (see Table A1 in the online supporting material). These alternative parameterizations, which technically required the introduction of an additional parameter, do not change our notion about the occurrence of additional bioenergetic costs and, importantly, they do not affect the outcome of the predation scenarios. In fact they give quantitative predictions for the alternative sources of bioenergetic costs that are experimentally testable, e.g. by measuring ingestion rates.

\section{Costs of induced life history shifts and adaptive value}

In 18 clones the life-history shift in response to fish kairomone was associated with costs, i.e. the fish-induced life-history yielded on average a lower population growth rate in an environment without size-selective predation than the corresponding non-induced life-history. Besides additional bioenergetic costs, the reduced somatic growth in the fish treatments was responsible for the lowered population growth rate. This is the case because net production of Daphnia is strongly size-dependent (Lynch et al. 1986) and lowered somatic growth will reduce net production in future. In consequence, a certain intensity of size-selective predation has to be surpassed in order to make the lifehistory shift adaptive indicating that such high predation intensities are occasionally prevailing in the environment of the respective clones. In principle, this result corresponds to the classic theory of inducible defenses, which states that defenses are costly and therefore not continuously expressed (Harvell 1990). However, in four clones no costs for the defenses have been detected and defenses were always advantageous. We further showed that there exists a large region in the trait space where no costs of the life-history shift occurred (Fig. 8). The puzzling phenomenon of no apparent costs of induced defenses suggests that other tradeoffs are involved, making the evolution as an inducible defense understandable. Tollrian and Dodson (1999) differentiated allocation costs, i.e. costs associated with shifting the resource allocation, from environmental costs, 
which are imposed by environmental variability. A likely environmental costs is the reduced starvation resistance of induced Daphnia phenotypes: smaller neonates (e.g. induced by fish kairomones) were proven to be less resistant to stressors like starvation (Cleuvers et al. 1997, Gliwicz and Guisande 1992, Stibor and Müller-Navarra 2000). In general, larger individuals are believed to be better competitors for food (Brooks and Dodson 1965, Hülsmann et al. 2005). In a broader theoretical approach on environmental costs, Gabriel et al. (2005) showed that environmental change favors the evolution of inducible defenses. In a changing environment a costly mismatch between the expressed defense and the actual environment can occur. This is, for example, the case when predators with different size preferences in the environment become abundant (Tollrian 1995). To slow down an individual's somatic growth in response to fish infochemicals would be costly when predation turns out to be negatively sizeselective, which is typically the case when invertebrate predators like Chaoborus or Leptodora are abundant (Lynch 1979).

The fact that life history shifts in single clones turn into an adaptive advantage at quite different levels of predation intensity lead to the expectation of a different sensitivity to fish kairomone. It also suggests that the predation intensity in the original habitat of a given clone regularly surpasses the critical predation intensity of that clone. This presumed variability in the type of predation and its intensity (e.g. due to the presence of different predators, changing predator's size, spatial differences) has been used as an explanation why there is so much genetic variation in fish-mediated lifehistory shifts (Boersma et al. 1998, De Meester and Weider 1999). From an evolutionary perspective differential sensitivity to kairomones may also be expected because the information derived from the kairomone is always associated with a distinct uncertainty: the response is mediated by an infochemical and, thus, not directly related to the ultimate factor, i.e. in our case to size-selective predation. Since it has been shown that daphnids cannot differentiate the cues from different fish species (von Elert and Pohnert 2000) not all kairomone in the environment necessarily has to stem from planktivorous fish.

The clones 1-9 from De Meester and Weider (1999) exclusively express life-history shifts in response to fish cues ('risk-tolerant', see methods) whereas clones 10-22 also showed behavioral defense mechanisms (diurnal vertical migration) in addition to life-history responses ('riskaverse'). The latter group is characterized by larger body sizes, which is mirrored by significantly higher values of $\kappa$ $(p=0.036$, Welch two sample t-test). Since this group of clones spatially escapes predation by migrating into deep waters they can tolerate larger body size in presence of a positively size-selective predator. Their life-history response in terms of the relative decrease in $\kappa$ in response to predator cues was not different from the response of the risk-tolerant group ( $p=0.41$, Welch two sample t-test). Although they shifted their life-history similarly, clones from the migrating group often showed lower additional bioenergetic costs associated with their life-history response. This difference was only weakly significant $(\mathrm{p}=0.06$, Welch two sample $\mathrm{t}$ test) but this effect is in line with our finding that the additional bioenergetic costs scale with $\kappa$.
Additionally, we evaluated data from Weber et al. (2003) on life-history-shifts of D. galeata in response to kairomones from Chaoborus larvae, a negatively sizeselective predator. These clones on average reacted by increasing somatic growth (higher $\kappa$, Table A2 in the online supporting material). We found this increase in $\kappa$ on average to be associated with a decrease in $\mathrm{C}_{\mathrm{E}}$. Altogether, these facts support our finding that additional bioenergetic costs tend to decrease if individuals become larger. We speculate that smaller individuals might have a higher physiological stress arising from higher specific physiological rates; a hypothesis that is also mirrored by the fact that smaller individuals on average suffer from faster ageing and decreased longevity (Speakman 2005).

\section{Direct vs indirect effects of predation}

Our analysis is also able to separate direct costs of predation from indirect costs. The direct effect of predation is the removal of individuals from the population as reflected by the negative slope of the lines in Fig. 6, i.e. a decreasing population growth rate with increasing predation intensity. The indirect effect of predation in our system is the shifted resource allocation strategy and the associated bioenergetic costs. These indirect effects are independent from the predation itself and occur also if there is no size-selective predation active. These costs are reflected by the shift in the intercept between both lines in each plot in Fig. 6. Such trait-mediated indirect effects of predation have been found in various predator prey systems and can be even more important for the prey population than the direct predation effect (Peacor and Werner 2001). A typical trait mediating these indirect effects is activity level and energy intake: in amphibian larvae, for example, it has been shown that tadpoles reduce activity in presence of predators (e.g. larval dragonfly), which reduces food intake and growth rate (Peacor and Werner 2001, Richardson 2001b). Modulation of activity levels in response to predators is also predicted from theoretical studies (Werner and Anholt 1993). Since decreasing activity is associated with lower resource acquisition rates it indirectly also leads to a lower competitive value making the respective species more vulnerable to competitive exclusion (Peacor and Werner 1997). Models therefore predict that consequences of these indirect effects are particularly pronounced if prey density is high and resources are close to minimal requirements (Peacor and Werner 2000).

In conclusion, the analysis presented in this study allowed us to disentangle resource allocation patterns underlying predator-induced life history shifts and to quantify costs and benefits associated with this induced defense. We believe that this is the first study that puts resource allocation, energetic costs and adaptive value of predator induced life-history shifts-using experimental data of an important model organism-into one theoretical framework. We show that Daphnia invests less energy in somatic growth in the fish treatment. At the same time several clones clearly showed additional energetic costs in the fish treatments. Consequently, the response to fish kairomones only becomes adaptive if the intensity of size selective predation surpasses a certain critical level. It is 
tempting to extend this analysis to include the performance at different food concentrations, or even more interesting, to include food dynamics (for a first attempt in that direction see Rinke and Vijverberg 2005). This could pave the way to analyze scenarios representing the natural environment (in terms of food and predation) in which the variety of observed life history strategies has evolved. Such an analysis would be another step forward in the integration of physiological, ecological and evolutionary research for an important model organism.

Acknowledgements - We wish to thank Jürgen Benndorf and Thomas Petzoldt for discussions and their encouragement to conduct this work. Susanne Rolinski helped to improve the english. Thanks also to Koos Vijverberg for initializing discussions about Daphnia life-history. Very valuable comments for improving the content of the manuscript have been given by Volker Grimm and Wilfried Gabriel. KR was supported by the German Bundesministerium für Bildung und Forschung under grant 02 WT 0233 and by Deutsche Forschungsgemeinschaft (DFG, grant RO 1008/11-1). SH was partly supported by the Deutsche Forschungsgemeinschaft (DFG, grant Be 1671/8-2).

\section{References}

Beckerman, A. et al. 2007. Behavioural versus physiological mediation of life history under predation risk. - Oecologia 152: 335-343.

Boersma, M. et al. 1998. Predator-mediated plasticity in morphology, life history, and behavior of Daphnia: the uncoupling of responses. - Am. Nat. 152: 237-248.

Bohrer, R. N. and Lampert, W. 1988. Simultaneous measurement of the effect of food concentration on assimilation and respiration in Daphnia magna Strauss. - Funct. Ecol. 2: 463-471.

Bottrell, H. H. 1975. Generation time, length of instar, instar duration and frequency of moulting, and their relationship to temperature in eight species of cladocera from the River Thames, Reading. - Oecologia 19: 129-140.

Bottrell, H. H. et al. 1976. A review of some problems in zooplankton studies. - Norw. J. Zool. 24: 419-456.

Brewer, M. C. et al. 1999. Interactive effects of fish kairomone and light on Daphnia escape behavior. - J. Plankton Res. 21: 1317-1335.

Brooks, J. L. and Dodson, S. I. 1965. Predation, body size, and the composition of the plankton. - Science 150: 28-35.

Cleuvers, M. et al. 1997. Life-strategy shift by intraspecific interaction in Daphnia magna: change in reproduction from quantity to quality. - Oecologia 110: 337-345.

Cryer, M. et al. 1986. Reciprocal interactions between roach, Rutilus rutilus, and zooplankton in a small lake: prey dynamics and fish growth and recruitment. - Limnol. Oceanogr. 31: 1022-1038.

De Meester, L. and Weider, L. J. 1999. Depth selection behavior, fish kairomones, and the life histories of Daphnia hyalina $\times$ galeata clones. - Limnol. Oceanogr. 44: 1248-1258.

De Meester, L. et al. 1999. Ecology and evolution of predatorinduced behavior of zooplankton: depth selection behavior and diel vertical migration. - In: Tollrian, R. and Harvell, C. D. (eds), The ecology and evolution of inducible defenses. Princeton Univ. Press, pp. 160-176.

Gabriel, W. 1982. Modelling reproductive strategies of Daphnia. - Arch. Hydrobiol. 95: 69-80.
Gabriel, W. et al. 2005. Environmental tolerance, heterogeneity, and the evolution of reversible plastic responses. - Am. Nat. 166: 339-353.

Gadgil, M. and Bossert, W. H. 1970. Life historical consequences of natural selection. - Am. Nat. 104: 1-24.

Gliwicz, Z. M. and Guisande, C. 1992. Family planning in Daphnia: resistance to starvation in offspring born to mothers grown at different food levels. - Oecologia 91: 463-467.

Harvell, C. D. 1990. The ecology and evolution of inducible defenses. - Q. Rev. Biol. 65: 323-340.

Heino, M. and Kaitala, V. 1996. Optimal resource allocation between growth and reproduction in clams: why does indeterminate growth exist? - Funct. Ecol. 10: 245-251.

Heino, M. and Kaitala, V. 1999. Evolution of resource allocation between growth and reproduction in animals with indeterminate growth. - J. Evol. Biol. 12: 423-429.

Hülsmann, S. et al. 2005. A quantitative test of the size efficiency hypothesis by means of a physiologically structured model. - Oikos 110: 43-54.

King, D. and Roughgarden, J. 1982. Graded allocation between vegetative and reproductive growth for annual plants in growing seasons of random length. - Theor. Popul. Biol. 22: $1-16$.

Kooijman, S. A. L. M. 1986. Population dynamics on the basis of budgets. - In: Metz, J. A. J. and Diekmann, O. (eds), The dynamics of physiologically structured populations. Springer, pp. 266-297.

Kooijman, S. A. L. M. 2000. Dynamic energy and mass budgets in biological systems. - University Press.

Kooijman, S. A. L. M. 2001. Quantitative aspects of metabolic organization: a discussion of concepts. - Philos. Trans. R. Soc. B 356: 331-349.

Köpke, U. et al. 1988. Analyse des Nahrungskonsums von Barschen (Perca fluviatilis) in der Talsperre Bautzen. - Limnologica 19: 37-47.

Kozlowski, J. 1992. Optimal allocation of resources to growth and reproduction-implications for age and size at maturity. - Trend. Ecol. Evol. 7: 15-19.

Laforsch, C. et al. 2004. An acoustic microscopy technique reveals hidden morphological defenses in Daphnia.- Proc. Natl Acad. Sci. USA 101: 15911-15914.

Law, R. 1979. Optimal life histories under age-specific predation. - Am. Nat. 114: 399-417.

Lynch, M. 1979. Predation, competition, and zooplankton community structure: an experimental study. - Limnol. Oceanogr. 24: 253-272.

Lynch, M. 1980. The evolution of cladoceran life histories. - Q. Rev. Biol. 55: 23-42.

Lynch, M. et al. 1986. Measurement of the carbon balance in Daphnia. - Limnol. Oceanogr. 31: 17-33.

McPeek, M. A. 1998. The consequences of changing the top predator in a food web: a comparative experimental approach. - Ecol. Monogr. 68: 1-23.

McPeek, M. A. 2004. The growth/predation risk tradeoff: so what is the mechanism? - Am. Nat. 163: E88-E111.

Mehner, T. et al. 1998. Gape-size dependent feeding of age-0 perch (Perca fluviatilis) and age-0 zander (Stizostedion lucioperca) on Daphnia galeata. - Arch. Hydrobiol. 142: 191-207.

Mills, E. L. and Forney, J. L. 1983. Impact on Daphnia pulex of predation by young yellow perch in Oneida Lake, New York. - Trans. Am. Fish. Soc. 112: 151-161.

Muck, P. and Lampert, W. 1984. An experimental study on the importance of food conditions for the relative abundance of calanoid copepods and cladocerans 1. comparative feeding studies with Eudiaptomus gracilis and Daphnia longispina. - Arch. Hydrobiol. Suppl. 66: 157-179. 
Niewiarowski, P. H. 2001. Energy budgets, growth rates, and thermal constraints: toward an integrative approach to the study of life-history variation. - Am. Nat. 157: 421-433.

Nisbet, R. M. et al. 2000. From molecules to ecosystems through dynamic energy budget models. - J. Anim. Ecology 69: 913926.

Noonburg, E. G. and Nisbet, R. M. 2005. Behavioural and physiological responses to food availability and predation risk. - Evol. Ecol. Res. 7: 89-104.

Peacor, S. D. and Werner, E. E. 1997. Trait-mediated indirect interactions in a simple aquatic food web.- Ecology 78: 11461156.

Peacor, S. D. and Werner, E. E. 2000. Predator effects on an assemblage of consumers through induced changes in consumer foraging behavior. - Ecology 81: 1998-2010.

Peacor, S. D. and Werner, E. E. 2001. The contribution of traitmediated indirect effects to the net effects of a predator. - Proc. Natl Acad. Sci. USA 98: 3904-3908.

Porter, K. G. et al. 1982. The effect of food concentration on swimming patterns, feeding behaviour, ingestion, assimilation, and respiration by Daphnia. - Limnol. Oceanogr. 27: 935949.

Ramcharan, C. W. et al. 1992. Predation risk, prey behavior, and feeding rate in Daphnia pulex. - Can. J. Fish. Aquat. Sci. 49: 159-165.

Ren, J. S. and Ross, A. H. 2005. Environmental influence on mussel growth: a dynamic energy budget model and its application to the greenshell mussel Perna canaliculus.- Ecol. Modell. 189: 347-362.

Reznick, D. 1982. The impact of predation on life-history evolution in Trinidadian guppies-genetic-basis of observed life-history patterns. - Evolution 36: 1236-1250.

Richardson, J. M. L. 2001a. A comparative study of activity levels in larval anurans and response to the presence of different predators. - Behav. Ecol. 12: 51-58.

Richardson, J. M. L. 2001b. The relative roles of adaptation and phylogeny in determination of larval traits in diversifying anuran lineages. - Am. Nat. 157: 282-299.

Riessen, H. P. 1999. Predator-induced life history shifts in Daphnia: a synthesis of studies using meta-analysis.- Can. J. Fish. Aquat. Sci. 56: 2487-2494.

Rinke, K. and Vijverberg, J. 2005. A model approach to evaluate the effect of temperature and food concentration on individual life-history and population dynamics of Daphnia. - Ecol. Modell. 186: 326-344.

Shertzer, K. W. and Ellner, S. P. 2002. State-dependent energy allocation in variable environments: life history evolution of a rotifer. - Ecology 83: 2181-2193.

Spaak, P. et al. 2000. Predator-induced life history changes and the coexistence of five taxa in a Daphnia species complex. - Oikos 89: 164-174.

Speakman, J. R. 2005. Body size, energy metabolism and lifespan. - J. Exp. Biol. 208: 1717-1730.

Spitze, K. et al. 1991. The covariance structure of life-history characters in Daphnia pulex. - Evolution 45: 1081-1090.

Stearns, S. C. 1992. The evolution of life histories. - Oxford Univ. Press.

Stibor, H. 1992. Predator induced life-history shifts in a freshwater cladoceran. - Oecologia 92: 162-165.

Stibor, H. and Lampert, W. 1993. Estimating the size at maturity in field populations of Daphnia (Cladocera).-- Freshwater Biol. 30: 433-438.

Stibor, H. and Lüning, J. 1994. Predator-induced phenotypic variation in the pattern of growth and reproduction in Daphnia hyalina (Crustacea: Cladocera). - Funct. Ecol. 8: 97-101.
Stibor, H. and Müller-Navarra, D. 2000. Constraints on the plasticity of Daphnia magna influenced by fish-kairomones. - Funct. Ecol. 14: 455-459.

Taylor, B. E. and Gabriel, W. 1992. To grow or not to grow: optimal resource allocation for Daphnia. - Am. Nat. 139: 248-266.

Taylor, B. E. and Gabriel, W. 1993. Optimal adult growth of Daphnia in a seasonal environment. - Funct. Ecol. 7: 513521.

Tollrian, R. 1995. Predator-induced morphological defences: costs, life history shifts, and maternal effects in Daphnia pulex. - Ecology 76: 1691-1705.

Tollrian, R. and Dodson, S. I. 1999. Inducible defenses in cladocera: constraints, costs, and multipredator environments. - In: Tollrian, R. and Harvell, C. D. (eds), The ecology and evolution of inducible defenses. Princeton Univ. Press, pp. 177-202.

Tollrian, R. and Harvell, C. D. (eds) 1999. The ecology and evolution of inducible defenses. - Princeton Univ. Press.

Urabe, J. and Watanabe, Y. 1990. Influence of food density on respiration rate of two crustacean plankters, Daphnia galeata and Bosmina longirostris. - Oecologia 82: 362-368.

Urabe, J. and Watanabe, Y. 1991. Effect of food concentration on the assimilation and production efficiencies of Daphnia galeata G.O. Sars (Crustacea, Cladocera).- Funct. Ecol. 5: 635-641.

van der Veer, H. W. et al. 2003. Body size scaling relationships in flatfish as predicted by dynamic energy budgets (DEB theory): implications for recruitment. - J. Sea Res. 50: 255-270.

von Bertalanffy, L. 1957. Quantitative laws in metabolism and growth. - Q. Rev. Biol. 32: 217-231.

von Elert, E. and Pohnert, G. 2000. Predator specifity of kairomones in diel vertical migration of Daphnia: a chemical approach. - Oikos 88: 119-128.

Wagner, A. et al. 2004. Initiation of the midsummer decline of Daphnia as related to predation, non-consumptive mortality and recruitment: a balance. - Arch. Hydrobiol. 160: 1-23.

Wahl, C. M. et al. 1993. Ontogenetic changes in prey selection and visual acuity of the yellow perch, Perca flavescens. - Can. J. Fish. Aquat. Sci. 50: 743-749.

Weber, A. et al. 2003. The supposed lack of trade-off among Daphnia galeata life history traits is explained by increased adult mortality in Chaoborus conditioned treatments. Hydrobiologia 491: 273-278.

Weider, L. J. and Pijanowska, J. 1993. Plasticity of Daphnia life histories in response to chemical cues from predators. - Oikos 67: 385-392.

Werner, E. E. and Hall, D. J. 1974. Optimal foraging and the size selection of prey by the bluegill sunfish (Lepomis macrochirus). - Ecology 55: 1042-1052.

Werner, E. E. and Anholt, B. R. 1993. Ecological consequences of the tradeoff between growth and mortality-rates mediated by foraging activity. - Am. Nat. 142: 242-272.

Zaffagnini, F. 1987. Reproduction in Daphnia. - In: Peters, R. H. and De Bernardi, R. (eds), Daphnia. Mem. Ist. Ital. Idrobiol., pp. 245-284.

\section{Appendix 1.}

A1 (Alternative ways of parameterization) and A2 (Parameter estimation for life-history shifts of Daphnia in response to Chaoborus) are available online as Appendix O16099 at www.oikos.ekol.lu.se 